\title{
PENGEMBANGAN INSTRUMEN TES HIGHER ORDER THINKING SKILLS (HOTS) MATEMATIKA SMA KELAS X
}

\author{
K.O. Litna ${ }^{1}$, N.M.S. Mertasari ${ }^{2}$, G. Sudirtha ${ }^{3}$ \\ ${ }^{123}$ Program Studi Penelitian dan Evaluasi Pendidikan \\ Universitas Pendidikan Ganesha \\ Singaraja, Indonesia \\ e-mail: kameliaolga55@gmail.com ${ }^{1}$, srimertasarimade@yahoo.co.id ${ }^{2}$, \\ gede.sudirtha@undiksha.ac.id ${ }^{3}$
}

\begin{abstract}
Abstrak
Tujuan penelitian ini adalah untuk mengembangkan instrument tes high order thinking skills (HOTS) matematika SMA kelas X. Penelitian ini merupakan penelitian pengembanganan instrumen dengan mengikuti langkah-langkah pengembangan yang dikemukakan oleh Mardapi, yang terdiri dari dua tahap yakni tahap perancangan (menyusun spesifikasi tes, menulis soal, dan menelaah soal) dan tahap uji coba (melakukan uji coba tes, menganalisis butir soal, dan merakit tes). Subjek ujicoba diambil dengan teknik purposive sampling. Hasil penelitian menunjukan dari 25 butir tes yang diujicobakan terdapat 20 butir tes yang memenuhi standar kualitas tes HOTS. Semua butir tes yang diujicobakan dinyatakan valid. Reliabilitas tes sebesar 0,803 dengan kategori sangat tinggi. Tingkat kesukaran dengan kategori sedang sebanyak 14 butir tes dan 9 butir tes dengan kategori sukar. Berdasarkan analisis menggunakan item respon butir diperoleh siswa dengan kemampuan rendah mampu menjawab tes matematika berbasis HOTS dengan benar sebanyak 19,19\%, siswa dengan kemampuan sedang mampu menjawab tes matematika berbasis HOTS dengan benar sebanyak $63,51 \%$. Sedangkan siswa dengan kemampuan tinggi mampu menjawab tes matematika berbasis HOTS sebanyak $92,75 \%$. Hasil penelitian menunjukan bahwa instrumen tes yang dikembangkan telah memenuhi kategori instrumen tes HOTS yang berkualitas, sehingga instrumen tes yang dikembangkan dapat digunakan untuk mengukur kemampuan HOTS matematika siswa. Instrumen tes yang dihasilkan dapat dijadikan contoh bagi guru dalam membuat soal berbasis HOTS.
\end{abstract}

Kata kunci: HOTS; Instrumen Tes; Matematika Kelas X

\begin{abstract}
This research aims to develop the test instrument of high order thinking of Mathematic on High School class $X$. This is instrument development research based on development steps proposed by Mardapi, consists two steps, namely the design step (compile test specifications, write a question, and review the question) and the trial step (trial, analize, and assemble test). The Sampling mehod in this research is purposive sampling. The result showed that of 25 items tested, 20 items test comply the HOTS quality standards test. All items valid. The test realibility is 0,803 with very high category. There are 14 test items with medium difficulty level, and 9 test items with hard difficulty level. Based on analysis using respon item, the result showed students with low competency can answer HOTS based math test correctly ammounted to $19,19 \%$, students with intermediary competency can answer HOTS based math test ammounted to $63,51 \%$. While the students with high competency can answer the HOTS based math test ammounted to 92,75\%. The results showed that the test instruments developed have met the category of quality HOTS test instruments, so that the test instruments developed can be used to measure students' hots math abilities. The resulting test instruments can be used as an example for teachers in creating HOTS-based questions.
\end{abstract}

Keywords: HOTS; Test Instrument Development; Math Grade 


\section{PENDAHULUAN}

Pendidikan saat ini berada di masa pengetahuan (knowledge age) dengan percepatan peningkatan pengetahuan yang sangat cepat. Percepatan peningkatan pengetahuan ini didukung oleh penerapan media dan teknologi digital yang disebut dengan information super highway (Gates, 1996). Di abad ke 21 , pendidikan sangatlah penting untuk menghasilkan peserta didik yang memiliki keterampilan belajar dan berinovasi, keterampilan menggunakan teknologi dan media informasi, serta dapat bekerja, dan bertahan dengan menggunakan kecakapan hidup (life skills).

$$
\text { Binkley (2012) mengatakan }
$$

setidaknya ada empat yang harus dimiliki oleh generasi abad 21, diantaranya adalah: ways of thinking, ways of working, tools for working and skills for living in the world. Pertama: ways of thinking, cara berfikir yaitu kemampuan berfikir yang harus dikuasai peserta didik untuk menghadapi dunia abad 21 adalah kreatif, berfikir kritis, pemecahan masalah, pengambilan keputusan dan pembelajar. Ways of working, kemampuan bekerja dengan dunia yang global dan dunia digital, yakni communication and collaboration. Generasi abad 21 dituntut mampu berkomunikasi dengan baik juga berkolaborasi dan bekerja sama dengan individu maupun komunitas dan jaringan. Ketiga: Tools for working adalah kemampuan penguasaan terhadap Information and communications technology (ICT) and information literacy. Dan Keempat: Skills for living in the world, kemampuan untuk menjalani kehidupan di abad 21, yaitu: Citizenship, life and career, personal and social responsibility.

Rotherham \& Willingham (2009) mengatakan bahwa kesuksesan seorang peserta didik tergantung pada kecakapan abad 21, sehingga peserta didik dituntut agar mampu memiliki kecakapan tersebut. Kecakapan-kecakapan tersebut diantaranya adalah kecakapan memecahkan masalah (problemsolving), berpikir kritis (critical thinking), kolaborasi, dan kecakapan berkomunikasi. Hal ini sangat berpengaruh pada kurikulum pendidikan Indonesia dalam mengadopsi kompetensi abad 21 ke dalam materi pelajaran di sekolah, termasuk matematika. Pendidikan di abad 21 seharusnya dapat memberikan pengalaman baru, ide-ide unik dan kreatif, dan mengembangkan atti-tudes kolaboratif sebagai modal pelajar untuk menghadapi dunia kerja, bergaul dengan masyarakat, dan menjalani kehidupan sehari-hari (Hamdi, dkk: 2018).

Pelaksanaan kegiatan pembelajaran khususnya pembelajaran matematika dalam menghadapi abad 21 harus diarahkan dengan baik sehingga mampu menghasilkan peserta didik yang berpikir kritis (critical thinking), berkolaborasi, dan berkomunikasi dengan baik. Pembelajaran matematika erat kaitannya dengan berbagai permasalah yang harus dipecahkan oleh peserta didik. Pembelajaran matematika memiliki prinsip yaitu matematika sebagai pemecahan masalah, matematika sebagai penalaran matematika sebagai komunikasi dan matematika sebagai hubungan, (Suherman, 2013). Kajian pembelajaran matematika harus didesain lebih otentik agar memberi tantangan kepada peserta didik sehingga mampu berkolaborasi menciptakan solusi dalam memecahkan masalah pelajaran. Pemecahan masalah mengarah ke pertanyaan dan mencari jawaban oleh peserta didik yang kemudian dapat dicari solusi dalam konteks pembelajaran menggunakan sumber daya informasi yang tersedia (Trilling and Hood, 1999). Preferensi utama dari suatu sistem pendidikan di abad 21 ini yaitu dapat mendidik peserta didik tentang bagaimana cara belajar dan mendorong siswa agar mampu berpikir tingkat tinggi sehingga mampu menghadapi perubahan dunia. Oleh karena itu, dalam menghadapi tuntutan di abad 21 pembelajaran hendaknya dilakukan dengan berorientasi pada kegiatan yang mampu meningkatkan kemampuan berpikir tingkat tinggi peserta didik.

Kemampuan berpikir tigkat tinggi atau yang sering disebut higher order thinking skills (HOTS) merupakan suatu proses berpikir peserta didik pada level kognitif yang lebih tinggi yang dikembangkan dari berbagai konsep dan metode kognitif dan taksonomi 
pembelajaran seperti metode problem solving (Saputra, 2016). Pada level HOTS, siswa tidak hanya dituntut untuk menghafal konsep yang diberikan, akan tetapi siswa mampu mengapilkasikan konsep tersebut dalam menyelesaikan masalah yang disajikan. . Dalam Kemendikbud 2017 dipaparkan bahwa kemampuan berpikir tingkat tinggi termasuk kemampuan untuk memecahkan masalah (problem solving), keterampilan berpikir kritis (critical thinking), berpikir kreatif (creative thinking), kemampuan berargumen (reasoning), dan kemampuan mengambil keputusan (decision making). King, Goodson, dan Rohani (2004) menyebutkan keterampilan yang termasuk dalam HOTS atau keterampilan berpikir tingkat tinggi adalah berpikir kritis, logis, reflektif, metakognitif, dan kreatif." Pada level HOTS, siswa tidak hanya dituntut untuk menghafal konsep yang diberikan, akan tetapi siswa mampu mengaplikasikan konsep tersebut dalam menyelesaikan masalah yang disajikan.

Widana (2017) mengatakan bahwa HOTS adalah kegiatan berpikir yang menuntut adanya transfer antar konsep, pemrosesan informasi, pengaitan berbagai informasi yang berbeda, pemanfaatan informasi untuk pemecahan masalah, dan pengkajian informasi secara kritis. Segala kegiatan berpikir dalam kategori HOTS ini, yakni transfer antar konsep, pemrosesan informasi, keterkaitan berbagai informasi berbeda, pemanfaatan informasi untuk pemecahan masalah, dan pengkajian informasi secara kritis akan memungkinkan dihasilkan ideide baru yang lebih segar, dan produk baru yang lebih baik. Sehingga, pengembangan HOTS dilakukan dengan tujuan untuk mencetak generasi pembangun bangsa, bukan generasi yang membebani bangsa. Dengan HOTS, peserta didik tidak hanya memiliki pengetahuan hanya sebatas memahami konsep yang ada, namun mampu mengait-ngaitkan informasi yang satu dengan yang lain, menganalis kondisi yang ada dengan informasi yang dimiliki, mengkaji kekuatan dan kekurangannya dan memunculkan ide baru yang bermanfaat bagi kehidupan yang lebih baik. Karena itu, pengembangan HOTS merupakan hal yang sangat penting untuk dilakukan oleh semua guru, termasuk guru matematika, karena HOTS harus dimiliki oleh generasi emas Indonesia.

Mengacu kepada taksonomi Bloom yang telah disempurkan oleh Anderson \& Krathwohl (2001), dimensi proses berpikir terdiri atas kemampuan: mengetahui (knowing-C1), memahami (understandingC2), menerapkan (aplying-C3), menganalisis (evaluating-C5), dan mengkreasi (creating-C6). Dimensi berpikir C1 dan $\mathrm{C} 2$ dikelompokkan ke dalam level kognitif 1 (Low Order Thinking Skills/LOTS), C3 pada level kognitif 2 (Middle Order Thinking Skills/MOTS), dan C4 sampai C6 pada level kognitif 3 (High Order Thinking Skills/HOTS). Menganalisis (C4) yaitu kemampuan memisahkan konsep ke dalam beberapa komponen dan menghubungkan satu sama lain untuk memperoleh pemahaman atas konsep secara utuh, mengevaluasi (C5) yaitu kemampua menetapkan derajat sesuatu berdasarkan norma, kriteria atau patokan tertentu, dan mencipta (C6) yaitu kemampuan memadukan unsur-unsur menjadi sesuatu bentuk baru yang utuh dan luas, atau membuat sesuatu yang orisinil.

Dalam praktek pelaksanaan kegiatan pembelajaran tidak akan terlepas dari proses penilaian. Yong dan Sam (2008) mengemukakan bahwa penilaian memainkan peran utama dalam pendidikan matematika. Hasil penilaian juga mampu memotivasi peserta didik untuk meningkatkan prestasinya. Penilaian hasil belajar yang diharapkan merupakan bentuk penilaian yang dapat membantu peserta didik untuk meningkatkan kemampuan berpikir tingkat tinggi (Higher Order Thinking Skills/HOTS), karena berpikir tingkat tinggi dapat mendorong peserta didik untuk berpikir secara luas dan mendalam tentang materi pelajaran. Penilaian yang mengadopsi praktik HOTS merupakan salah satu langkah yang dilakukan untuk meningkatkan kualitas pendidikan yang memiliki standar internasional. Penilaian berbasis HOTS merupakan bentuk penilaian yang mendukung pendidikan di abad 21. Penyajian soal-soal HOTS dalam 
Penilaian dapat melatih peserta didik untuk mengasah kemampuan dan keterampilannya sesuai dengan tuntutan kompetensi abad ke-21 di atas. Melalui penilaian berbasis pada soal-soal HOTS, keterampilan berpikir kritis (creative thinking and doing), kreativitas (creativity) dan rasa percaya diri (learning self reliance), akan dibangun melalui kegiatan latihan menyelesaikan berbagai permasalahan nyata dalam kehidupan sehari-hari (problem-solving).

Pelaksanaan penilaian tidak terlepas dari instrumen penilaian yang dibuat dalam bentuk soal-soal baik untuk menguji kemampuan kognitif, afektif, maupun psikomotor. Instrumen merupakan alat bantu yang digunakan dalam mengumpulkan data atau informasi (Arikunto, 2002). Instrumen berfungsi untuk mendapatkan data yang diperlukan ketika siswa telah melewati proses pembelajaran sampai akhir. Kualitas instrumen penilaian berpengaruh langsung terhadap tingkat keakuratan status pencapaian hasil belajar peserta didik. Instrumen tes yang berbasis HOTS mencakup dimensi kognitif yang tinggi yaitu C4 (menganalisis), C5 (mengevaluasi), dan C6 (menciptakan). Adapun karakteristik soal-soal HOTS adalah mengukur kemampuan tingkat tinggi, berbasis permasalahan kontekstual, menggunakan bentuk soal beragam, dan penyusunan menggunakan Taksonomi Bloom yang berada dalam kategori kemampuan berpikir tingkat tinggi (Kemendikbud 2017). Conklin (2012) menyatakan bahwa karakteristik HOTS yaitu "characteristics of higher-order thinking skills: higher-order thinking skills encompass both critical thinking and creative thinking". Maksudnya, karakteristik kemampuan berpikir tingkat tinggi mencakup berpikir kritis dan berpikir kreatif.

Namun pada kenyataannya masih banyak guru yang membuat instrumen tes yang hanya mengukur kemampuan tingkat rendah siswa yaitu dimensi kognitif C1 (mengetahui) dan C2 (memahami). Permasalah yang terjadi di sekolah adalah pertanyaan yang digunakan dalam penilaian kognitif cenderung menguji lebih banyak pada aspek mengingat, sementara itu pertanyaan yang melatih keterampilan berpikir tingkat tinggi siswa cenderung tidak ada (Kusuma, dkk: 2017). Hal tersebut menyebabkan kurang terasahnya kemampuan berpikir tingkat tinggi siswa. Kurang terlatihnya kemampuan berpikir tingkat tingginya siswa juga dapat dilihat dari hasil PISA tahun 2018 untuk kemampuan matematika siswa Indonesia memperoleh skor 379 dengan peringkat ke 72 dari 78 negara yang berpartisipasi. Minimnya pengetahuan guru tentang pengembangan instrumen tes yang berbasis HOTS menjadi salah satu penyebab bahwa masih banyaknya guru yang memberikan soal yang hanya sekedar mengukur pemahaman tingkat rendah peserta didik. Rendahnya kemampuan berpikir tingkat tinggi siswa juga dapat dilhat dari urgensi penelitian yang dilakukan oleh Soeharto dan Rosmaiyadi (2018) yakni kemampuan berpikir siswa yang masih berada di Tingkat Lower Order Thinking Skills (LOTS) menjadi perhatian karena menjadi hambatan bagi siswa dalam memahami materi fisika diajarkan oleh guru.

Permasalahan tersebut dapat diatasi dengan melakukan pengembangan instrumen tes yang berbasis HOTS. Instrumen tes HOTS yang dikembangkan merupakan instrumen tes yang valid dan reliabel. Hasil penelitian yang dilakukan oleh Hardiani (2017) yang menngatakan bahwa proses penilaian hasil belajar siswa memerlukan instrumen yang harus dipersiapkan dan diperhatikan terlebih dahulu, agar tujuan pembelajaran dapat tercapai secara optimal. Pengaplikasian pengembangan instrumen tes HOTS ini mampu mengembangkan kemampuan berpikir tingkat tinggi peserta didik, serta memberikan contoh soal bentuk HOTS kepada guru.

Tujuan penelitian ini adalah untuk mengembangkan instrument tes high order thinking skills (HOTS) matematika SMA kelas $\mathrm{X}$.

\section{METODE}

Penelitian ini merupakan penelitian research and development (R\&D). Langkah-langkah pengembangan yang dilakukan dalam penelitian ini diadaptasi dari prosedur pengembangan yang 
dikemukakan oleh Djemari Mardapi (2008), yaitu: 1) menyusun spesifikasi tes, 2) menulis soal, 3) menelaah soal tes, 4) melakukan ujicoba tes, menganalisis butir soal, 6) memperbaiki tes, 7) merakit tes, 8) melaksanakan tes, 9) menafsir hasil tes. Langkah pengembangan yang dilakukan dalam penelitian ini terbatas sampai pada langkah merakit tes. Langkah-langkah pengembangan tersebut dikelompokan menjadi dua tahapan yakni tahap perancangan dan tahap ujicoba. Kegiatan yang dilakukan pada tahap perancangan adalah adalah menyusun spesifikasi tes, menulis soal, dan menelaah soal tes. 1) Menyusun spesifikasi tes, mencakup beberapa proses kegiatan, yakni: menentukan tujuan, menyusun kisi-kisi tes, memilih bentuk tes, dan menentukan panjang tes. 2) Menulis soal, Soal yang dibuat merupakan soal yang sesuai dengan indikator-indikator pada kisi-kisi yang telah dibuat. Penulisan soal yang dilakukan harus sesuai dengan kriteria HOTS. 3) Menelaah soal, menelaah soal tes yang telah disusun dilakukan guna untuk memperbaiki soal yang dalam pembutannya masih ada kekurangan ataupun kesalahan. Soal yang dibuat akan ditelaah para ahli/pakar dalam bidang pendidikan matematika dan evaluasi. Penelaahan ini dilakukan dengan mempertimbangkan tiga aspek dalam penyusunan tes yaitu: aspek materi, aspek konstruksi, dan aspek Bahasa (Heri Retnawati, 2016). Pada tahap uji coba beberapa prosedur yang perlu dilakukan, yakni: melakukan uji coba tes, menganalisis butir soal, memperbaiki tes, dan merakit tes. Uji coba tes yang dilakukan dalam penelitian ini dibedakan menjadi dua kelompok, yakni uji coba pada kelompok kecil dan uji coba pada kelompok besar.

Setelah dilakukan uji coba pada kelompok kecil selanjutnya akan di cari validitas, reliabilitas, tingkat kesukaran, kefektifan option, dan daya beda. Jika soal yang dibuat belum memenuhi kualitas yang diharapkan, berdasarkan hasil ujicoba tersebut dilakukan perbaikan. Setelah butir diperbaiki, selanjutnya butirbutir soal tersebut diujicobakan pada kelompok besar kemudian dilakukan analisis kuantitatif. Teknik analisis yang dialkukan pada penelitian ini menggunakan rumus berikut.

Validitas isi

$C V R=\frac{2 n e}{n}-1$

Validitas butir

$r_{p b i}=\frac{M_{p}-M_{t}}{s_{t}} \sqrt{\frac{p}{q}}$

Reliabilitas

$r_{11}=\left(\frac{k}{k-1}\right)\left(\frac{S D_{t}^{2}-\sum p q}{S D_{t}^{2}}\right)$

Tingkat kesukaran

$I=\frac{B}{N}$

Daya beda

$D_{B}=\frac{n B_{A}}{n_{A}}-\frac{n B_{B}}{n_{B}}$

Metode pengumpulan data adalah suatu prosedur yang menjelaskan cara perolehan data dalam suatu penelitan. Metode pengumpulan data yang digunakan dalam penelitian ini terdiri dari: studi dokumentasi, lembar validasi, dan tes. Bentuk tes yang digunakan merupakan tes pilihan ganda berbasis HOTS.

\section{HASIL DAN PEMBAHASAN}

Hasil pengembangan berupa pengembangan instrumen tes matematika berbasis HOTS. Langkah-langkah pengembangan yang dilakukan dalam penelitian ini diadaptasi dari prosedur pengembangan yang dikemukakan oleh Djemari Mardapi, yang dikelompokan menjadi dua tahapan yakni tahap perancangan dan tahap ujicoba. (1) Tahap perancangan, hasil penelitian pada tahap perancangan berupa kisi-kisi instrumen tes matematika SMA Kelas $X$ berbasis HOTS dan instrumen awal yang telah ditelaah oleh para judges/pakar. Kisi-kisi instrumen tes HOTS adalah suatu format yang mencantumkan kriteria yang diperlukan dalam menyusun instrument 
tes HOTS. Penyusunan Kisi-kisi instrumen tes HOTS dibuat dengan diawali menganalisis KD matematika SMA Kelas $X$ kurikulum 2013. KD yang digunakan merupakan KD yang memenuhi level kognitif C4 (menganalisis), C5 (mengevaluasi), dan C6 (mencipta). KD yang memenuhi syarat tersebut digunakan sebagai pedoman untuk pengembangan Indikator Pencapaian Kompetensi (IPK). Berdasarkan hasil analisis yang dilakukan terkait kualitas KD pelajaran matematika kelas $X$ ditinjau dari level HOTS terdapat dua KD yang memenuhi kriteria tersebut. Kedua KD tersebut sesuai dengan kriteria Taksonomi Bloom Revisi berada pada level HOTS C4/K2, sehingga kedua KD tersebut termasuk memenuhi syarat untuk dikembangkan dalam menyusun soal-soal HOTS. Mengacuh pada kedua KD yang memenuhi syarat, dibentuklah IPK yang dikembangkan disesuaikan dengan kata kerja operasional pada masing-masing level Taksonomi Bloom Revisi, serta memenuhi empat aspek yaitu: aspek materi, aspek konstruksi, aspek bahasa, dan kriteria HOTS. Dari hasil penelitian terdapat 2 indikator pada level proses kognitif C4, 2 indikator pada level proses kognitif C5, 1 indikator pada level proses kognitif C6. Berdasarkan indicator tersebut, disusunlah soal-soal matematika berbasis HOTS yang akan diujicobakan.

Selanjutnya, instrumen yang telah dibuat, ditelaah oleh judges/pakar. Banyaknya judges yang menelaah instrumen dalam penelitian ini adalah 7 (tujuh) orang. Berdasarkan penilaian ketujuh pakar terdapat dua indicator yang perlu diperbaiki dan dua soal yang belum memenuhi kriteria HOTS sehingga kedua soal tersebut perlu diganti dengan soal baru. Setelah dilakukan perbaikan, dinilai kembali pleh para pakar dan menunjukan hasil bahwa dari 28 butir tes yang dinilai semuanya relevan. Hasil penilaian tersebut kemudian dianalisis dengan menggunakan rumus lawshe sehingga diperoleh koefisien validitas isi soal matematika berbasis HOTS adalah 1 dengan kriteria baik.
Tahap ujicoba, ujicoba yang dilakukan dalam penelitian ini dibedakan menjadi dua kelompok, yakni uji coba pada kelompok kecil dan uji coba pada kelompok besar. Butir tes yang telah dianalisis validitas isinya selanjutnya diujicobakan pada subjek penelitian. Dikarenakan situasi pandemi, untuk mengurangi waktu berkumpul maka dari 28 butir tes yang dibuat, sebanyak 25 butir tes yang diujicobakan. Uji coba ini dilakukan di kelas XI dari empat sekolah negeri di Kabupaten Manggarai Timur, yakni: SMA Negeri 2 Borong, SMA Negeri 7 Borong, SMA Negeri 5 Kota Komba, dan SMA Negeri 7 Kota Komba. Banyaknya subjek uji coba pada uji coba kelompok kecil adalah 125 siswa. Sedangkan subjek uji coba pada kelompok besar sebanyak 250 siswa. Subjek uji coba dipilih mengunakan teknik purposive sampling yaitu pengambilan sampel dengan bantuan guru mata pelajaran matematika. Setelah dilakukan ujicoba selanjutnya adalah melakukan uji validitas butir tes, reliabilitas, tingkat kesukaran, daya beda, dan efektivitas option.

Pada uji coba kelompok kecil diperoleh validitas butir tes 25 butir tes dinyatakan valid. Reliabilitas, pada ujicoba kelompok kecil diperoleh koefisien reliabilitas sebesar 0,764 termasuk kategori derajat reliabilitas tinggi. Tingkat kesukaran butir tes diperoleh pada ujicoba kelompok kecil adalah terdapat 18 soal dengan kriteria sedang dan 7 soal dengan kriteria sukar. Daya beda, dari hasil penelitian untuk daya beda butir tes pada kelompok kecil terdapat satu butir soal dengan daya pembeda yang kurang baik, satu butir soal dengan daya pembeda cukup, 19 soal dengan daya pembeda baik, dan 4 soal dengan daya pembeda sangat baik. Secara keseluruhan semua butir memiliki option yang efektif. Secara terperinci dapat dilihat pada tabel berikut. 
Tabel 1. Ringkasan Hasil Validasi Soal Matematika Berbasis HOTS

\begin{tabular}{|c|c|c|c|c|c|c|c|c|}
\hline \multirow{2}{*}{$\begin{array}{l}\text { No. } \\
\text { Butir } \\
\text { Soal }\end{array}$} & \multicolumn{2}{|c|}{$\begin{array}{c}\text { Validitas Butir } \\
r_{\text {tabel }}=0,176\end{array}$} & \multicolumn{2}{|c|}{$\begin{array}{c}\text { Tingkat } \\
\text { Kesukaran }\end{array}$} & \multicolumn{2}{|c|}{ Daya Beda } & \multirow[t]{2}{*}{$\begin{array}{l}\text { Efektivitas } \\
\text { Option }\end{array}$} & \multirow[t]{2}{*}{ Kesimpulan } \\
\hline & $r_{\text {hitung }}$ & Kriteria & TK & Kriteria & $\mathrm{DB}$ & Kriteria & & \\
\hline 1 & 0,327 & Valid & 0,58 & Sedang & 0,41 & Baik & Efektif & Diterima \\
\hline 2 & 0,365 & Valid & 0,58 & Sedang & 0,47 & Baik & Efektif & Diterima \\
\hline 3 & 0,328 & Valid & 0,55 & Sedang & 0,41 & Baik & Efektif & Diterima \\
\hline 4 & 0,382 & Valid & 0,59 & Sedang & 0,44 & Baik & Efektif & Diterima \\
\hline 5 & 0,484 & Valid & 0,28 & Sukar & 0,71 & $\begin{array}{c}\text { Sangat } \\
\text { Baik }\end{array}$ & Efektif & Diterima \\
\hline 6 & 0,386 & Valid & 0,59 & Sedang & 0,47 & Baik & Efektif & Diterima \\
\hline 7 & 0,381 & Valid & 0,42 & Sedang & 0,53 & Baik & Efektif & Diterima \\
\hline 8 & 0,391 & Valid & 0,62 & Sedang & 0,47 & Baik & Efektif & Diterima \\
\hline 9 & 0,536 & Valid & 0,28 & Sukar & 0,71 & $\begin{array}{c}\text { Sangat } \\
\text { Baik }\end{array}$ & Efektif & Diterima \\
\hline 10 & 0,228 & Valid & 0,55 & Sedang & 0,24 & Cukup & Efektif & Ditolak \\
\hline 11 & 0,469 & Valid & 0,56 & Sedang & 0,56 & Baik & Efektif & Diterima \\
\hline 12 & 0,334 & Valid & 0,58 & Sedang & 0,47 & Baik & Efektif & Diterima \\
\hline 13 & 0,403 & Valid & 0,30 & Sukar & 0,50 & Baik & Efektif & Diterima \\
\hline 14 & 0,522 & Valid & 0,58 & Sedang & 0,71 & $\begin{array}{c}\text { Sangat } \\
\text { Baik }\end{array}$ & Efektif & Diterima \\
\hline 15 & 0,343 & Valid & 0,50 & Sedang & 0,41 & Baik & Efektif & Diterima \\
\hline 16 & 0,356 & Valid & 0,62 & Sedang & 0,41 & Baik & Efektif & Diterima \\
\hline 17 & 0,410 & Valid & 0,33 & Sedang & 0,50 & Baik & Efektif & Diterima \\
\hline 18 & 0,454 & Valid & 0,50 & Sedang & 0,56 & Baik & Efektif & Diterima \\
\hline 19 & 0,355 & Valid & 0,29 & Sukar & 0,41 & Baik & Efektif & Diterima \\
\hline 20 & 0,299 & Valid & 0,44 & Sedang & 0,41 & Baik & Efektif & Diterima \\
\hline 21 & 0,246 & Valid & 0,50 & Sedang & 0,18 & $\begin{array}{c}\text { Kurang } \\
\text { Baik }\end{array}$ & Efektif & Ditolak \\
\hline 22 & 0,357 & Valid & 0,26 & Sukar & 0,41 & Baik & Efektif & Diterima \\
\hline 23 & 0,349 & Valid & 0,47 & Sedang & 0,41 & Baik & Efektif & Diterima \\
\hline 24 & 0,386 & Valid & 0,29 & Sukar & 0,47 & Baik & Efektif & Diterima \\
\hline 25 & 0,562 & Valid & 0,26 & Sukar & 0,71 & $\begin{array}{c}\text { Sangat } \\
\text { Baik }\end{array}$ & Efektif & Diterima \\
\hline
\end{tabular}

Dari table 2, dapat disimpulkan bahwa terdapat dua butir soal yang ditolak, sehingga sebanyak 23 butir soal yang akan diujicobakan pada kelompok besar. Hasil uji coba kelompok besar menunjukan bahwa 23 butir soal yang diujicobakan valid. Koefisien reliabilitas 0,803 termasuk kategori derajat reliabilitas sangat tinggi. Tingkat kesukaran yang diperoleh terdapat 14 butir soal dengan kriteria sedang dan 9 soal dengan kriteria sukar. Selanjutnya, dengan koefisien tingkat kesukaran yang diperoleh dilakukan analisis teori respon butir satu parameter setiap butir tes. Dari hasil analisis menggunakan teori respon butir satu parameter secara keseluruhan menunjukan bahwa siswa yang berkemampuan tinggi, mampu menjawab soal matematika berbasis HOTS dengan benar sebanyak $92,75 \%$. Untuk siswa yang berkemampuan sedang, sebanyak $63,51 \%$. Sedangkan siswa yang berkemampuan rendah, sebanyak 19,19\%. Daya beda pada ujicoba kelompok besar yang diperoleh menunjukan 16 butir soal dengan daya pembeda yang baik dan 7 soal yang memiliki daya beda sangat baik. Dari hasil tersebut diperoleh bahwa semua butir memiliki nilai daya beda diatas 0,15. Hal ini menunjukan bahwa instrumen tes yang dikembangkan memiliki kualitas daya beda yang baik. 
Hasil analisis efektivitas option diperoleh bahwa terdapat tiga soal yang memiliki option tidak efektif, yakni butir soal nomor 1 (option A dan D), 8 (option A, $B$, dan $E$ ), dan 18 (option $D$ dan $E$ ).

Tabel 2. Rangkuman Hasil Uji-t pada Mahasiswa dengan Motivasi Tinggi

\begin{tabular}{|c|c|c|c|c|c|c|c|c|c|}
\hline \multirow{2}{*}{$\begin{array}{l}\text { No. } \\
\text { Butir } \\
\text { Soal }\end{array}$} & \multicolumn{2}{|c|}{$\begin{array}{c}\text { Validitas Butir } \\
r_{\text {tabel }}=0,138\end{array}$} & \multicolumn{2}{|c|}{$\begin{array}{c}\text { Tingkat } \\
\text { Kesukaran }\end{array}$} & \multirow[t]{2}{*}{ IRT } & \multicolumn{2}{|c|}{$\begin{array}{l}\text { Daya } \\
\text { Beda }\end{array}$} & \multirow[t]{2}{*}{$\begin{array}{c}\text { Efektivitas } \\
\text { Option }\end{array}$} & \multirow[t]{2}{*}{$\begin{array}{c}\text { Kesimpul } \\
\text { an }\end{array}$} \\
\hline & $r_{\text {hitung }}$ & $\begin{array}{c}\text { Kriteri } \\
\text { a }\end{array}$ & $\mathrm{TK}$ & $\begin{array}{c}\text { Krite } \\
\text { ria }\end{array}$ & & $\begin{array}{l}\mathrm{D} \\
\mathrm{B}\end{array}$ & $\begin{array}{c}\text { Kriteri } \\
\text { a }\end{array}$ & & \\
\hline 1 & 0,390 & Valid & 0,7 & $\begin{array}{l}\text { Sed } \\
\text { ang }\end{array}$ & $\begin{array}{l}45,01 \\
71 \%\end{array}$ & $\begin{array}{l}0 \\
5 \\
0\end{array}$ & Baik & $\begin{array}{c}\text { Tidak } \\
\text { Efektif (A } \\
\text { dan D) }\end{array}$ & Ditolak \\
\hline 2 & 0,539 & Valid & 0,3 & $\begin{array}{l}\text { Suk } \\
\text { ar }\end{array}$ & $\begin{array}{c}54,98 \\
29 \%\end{array}$ & $\begin{array}{l}0 \\
7 \\
4\end{array}$ & $\begin{array}{l}\text { Sang } \\
\text { at } \\
\text { Baik }\end{array}$ & Efektif & Diterima \\
\hline 3 & 0,397 & Valid & 0,5 & $\begin{array}{l}\text { Sed } \\
\text { ang }\end{array}$ & $50 \%$ & $\begin{array}{l}0 \\
4 \\
7\end{array}$ & Baik & Efektif & Diterima \\
\hline 4 & 0,543 & Valid & 0,5 & $\begin{array}{l}\text { Sed } \\
\text { ang }\end{array}$ & $50 \%$ & $\begin{array}{l}0 \\
7 \\
2\end{array}$ & $\begin{array}{l}\text { Sang } \\
\text { at } \\
\text { Baik }\end{array}$ & Efektif & Diterima \\
\hline 5 & 0,362 & Valid & 0,3 & $\begin{array}{l}\text { Suk } \\
\text { ar }\end{array}$ & $\begin{array}{c}54,98 \\
29 \%\end{array}$ & $\begin{array}{l}0 \\
4 \\
3\end{array}$ & Baik & Efektif & Diterima \\
\hline 6 & 0,387 & Valid & 0,5 & $\begin{array}{l}\text { Sed } \\
\text { ang }\end{array}$ & $50 \%$ & $\begin{array}{l}0 \\
4 \\
9\end{array}$ & Baik & Efektif & Diterima \\
\hline 7 & 0,374 & Valid & 0,5 & $\begin{array}{l}\text { Sed } \\
\text { ang }\end{array}$ & $50 \%$ & $\begin{array}{l}0 \\
5 \\
0\end{array}$ & Baik & Efektif & Diterima \\
\hline 8 & 0,372 & Valid & 0,7 & $\begin{array}{l}\text { Sed } \\
\text { ang }\end{array}$ & $\begin{array}{c}45,01 \\
71 \%\end{array}$ & $\begin{array}{l}0 \\
4 \\
6\end{array}$ & Baik & $\begin{array}{c}\text { Tidak } \\
\text { Efektif }(\mathrm{A}, \mathrm{B} \\
\text { dan } \mathrm{E})\end{array}$ & Ditolak \\
\hline 9 & 0,390 & Valid & 0,3 & $\begin{array}{l}\text { Suk } \\
\text { ar }\end{array}$ & $\begin{array}{c}54,98 \\
29 \%\end{array}$ & $\begin{array}{l}0 \\
4 \\
3\end{array}$ & Baik & Efektif & Diterima \\
\hline 11 & 0,543 & Valid & 0,5 & $\begin{array}{l}\text { Sed } \\
\text { ang }\end{array}$ & $50 \%$ & $\begin{array}{l}0 \\
7 \\
1\end{array}$ & $\begin{array}{l}\text { Sang } \\
\text { at } \\
\text { Baik }\end{array}$ & Efektif & Diterima \\
\hline 12 & 0,508 & Valid & 0,5 & $\begin{array}{l}\text { Sed } \\
\text { ang }\end{array}$ & $50 \%$ & $\begin{array}{l}0 \\
7 \\
1\end{array}$ & $\begin{array}{l}\text { Sang } \\
\text { at } \\
\text { Baik }\end{array}$ & Efektif & Diterima \\
\hline 13 & 0,362 & Valid & 0,5 & $\begin{array}{l}\text { Sed } \\
\text { ang }\end{array}$ & $50 \%$ & $\begin{array}{l}0 \\
4 \\
7\end{array}$ & Baik & Efektif & Diterima \\
\hline 14 & 0,386 & Valid & 0,3 & $\begin{array}{l}\text { Suk } \\
\text { ar }\end{array}$ & & $\begin{array}{l}0 \\
4 \\
4\end{array}$ & Baik & Efektif & Diterima \\
\hline 15 & 0,580 & Valid & 0,5 & $\begin{array}{l}\text { Sed } \\
\text { ang }\end{array}$ & $50 \%$ & $\begin{array}{l}0 \\
7 \\
4\end{array}$ & $\begin{array}{l}\text { Sang } \\
\text { at } \\
\text { Baik }\end{array}$ & Efektif & Diterima \\
\hline 16 & 0,501 & Valid & 0,5 & Sed & $50 \%$ & 0 & Sang & Efektif & Diterima \\
\hline
\end{tabular}




\begin{tabular}{|c|c|c|c|c|c|c|c|c|c|}
\hline & & & & ang & & $\begin{array}{l}7 \\
1\end{array}$ & $\begin{array}{c}\text { at } \\
\text { Baik }\end{array}$ & & \\
\hline 17 & 0,633 & Valid & 0,5 & $\begin{array}{l}\text { Sed } \\
\text { ang }\end{array}$ & $50 \%$ & $\begin{array}{l}0 \\
8 \\
2\end{array}$ & $\begin{array}{l}\text { Sang } \\
\text { at } \\
\text { Baik }\end{array}$ & Efektif & Diterima \\
\hline 18 & 0,366 & Valid & 0,7 & $\begin{array}{l}\text { Sed } \\
\text { ang }\end{array}$ & $\begin{array}{c}45,01 \\
71 \%\end{array}$ & $\begin{array}{l}0 \\
4 \\
3\end{array}$ & Baik & $\begin{array}{c}\text { Tidak } \\
\text { Efektif (D } \\
\text { dan E) }\end{array}$ & Ditolak \\
\hline 20 & 0,379 & Valid & 0,3 & $\begin{array}{l}\text { Suk } \\
\text { ar }\end{array}$ & $\begin{array}{c}54,98 \\
29 \%\end{array}$ & $\begin{array}{l}0 \\
4 \\
1\end{array}$ & Baik & Efektif & Diterima \\
\hline 22 & 0,391 & Valid & 0,3 & $\begin{array}{l}\text { Suk } \\
\text { ar }\end{array}$ & $\begin{array}{c}54,98 \\
29 \%\end{array}$ & $\begin{array}{l}0 \\
4 \\
1\end{array}$ & Baik & Efektif & Diterima \\
\hline 23 & 0,408 & Valid & 0,4 & $\begin{array}{l}\text { Sed } \\
\text { ang }\end{array}$ & $\begin{array}{c}52,49 \\
77 \%\end{array}$ & $\begin{array}{l}1 \\
0 \\
0\end{array}$ & Baik & Efektif & Diterima \\
\hline 24 & 0,333 & Valid & 0,3 & $\begin{array}{c}\text { Suk } \\
\text { ar }\end{array}$ & $\begin{array}{c}54,98 \\
29 \%\end{array}$ & $\begin{array}{l}0 \\
4\end{array}$ & Baik & Efektif & Diterima \\
\hline 25 & 0,372 & Valid & 0,3 & $\begin{array}{c}\text { Suk } \\
\text { ar }\end{array}$ & $\begin{array}{c}54,98 \\
29 \%\end{array}$ & $\begin{array}{l}1 \\
0 \\
4 \\
1\end{array}$ & Baik & Efektif & Diterima \\
\hline
\end{tabular}

Dari tabel 2 dapat diketahui bahwa dari 23 butir tes yang diujicobakan pada kelompok besar, terdapat tiga butir tes yang ditolak, sehingga 20 butir tes matematika yang memenuhi kualitas instrumen tes matematika berbasis HOTS.

\section{PENUTUP}

Secara umum hasil penelitian ini dapat disimpulkan bahwa dari 25 butir tes matematika SMA kelas $X$ yang berbasis HOTS yang dikembangkan, terdapat 20 butir tes yang diterima atau yang memenuhi standar kualitas instrumen tes HOTS yang baik. Semua butir tes memiliki validitas isi yang baik. Validitas butir tes yang diujicobakan baik pada ujicoba kelompok kecil maupun pada ujicoba kelompok besar menunjukan semua butir tes valid. Reliabilitas instrumen tes matematika SMA Kelas $X$ berbasis HOTS dinyatakan reliabel. Pada ujicoba kelompok kecil diperoleh koefisien reliabilitas sebesar 0,764 termasuk kategori derajat reliabilitas tinggi dan pada ujicoba kelompok besar diperoleh koefisien reliabilitas 0,803 termasuk kategori derajat reliabilitas sangat tinggi. Tingkat kesukaran yang diperoleh terdapat 14 soal berkategori sedang dan 9 soal berkategori sukar. Hasil analisis menggunakan teori respon butir satu parameter juga menunjukan bahwa siswa yang berkemampuan tinggi, mampu menjawab soal matematika berbasis HOTS dengan benar sebanyak $92,75 \%$. Untuk siswa yang berkemampuan sedang, sebanyak $63,51 \%$. Sedangkan siswa yang berkemampuan rendah, sebanyak $19,19 \%$. Terdapat 16 butir soal dengan daya pembeda yang baik dan 7 soal yang memiliki daya beda sangat baik. Sedangkan untuk efektivitas option diperoleh bahwa terdapat tiga soal yang memiliki option tidak efektif.

Saran diajukan kepada guru diharapkan kedepannya dalam 
membuat tes matematika guru lebih menekankan pada tes yang berbasis HOTS. Bagi guru-guru yang ingin mengembangkan instrument HOTS diharapkan terlebih dahulu melakukan uji validasi butir soal sebelum digunakan dan bila perlu menggunakan tahapan pengembangan butir soal sesuai dengan penelitian ini.

\section{DAFTAR RUJUKAN}

Anderson \& Krathwohl. 2001. A Taxonomy For Learning, Teaching, and Assessing; A revision of Bloom's Taxonomy of Education Objectives. New York: Addison Wesley Lonman Inc..

Anshari, H. 2017. Pengaruh Pendekatan Realistik Terhadap Kemampuan Komunikasi Matematika Komunikasi Matematika dan Self Efficacy Siswa SMP Taman Harapan Medan". Tesis Program Pascasarjana Universitas Negeri Medan. No 2,Volume 5. Diakses tanggal 30 Maret 2020.

Binkley, M. 2012. Defining Twenty-First Century Skills. London: Springer

Conklin, W. 2012. Higher order thinking skills to develop 21stcentury learners. Huntington Beach, California: Shell Education.

Gates, Bill; Myhrvold, Nathan and Rinearson, Peter. 1996. The Road Ahead, Penguin Books. ISBN 978-0-14-026040-3.

Hamdi; Suganda; and Hayati. 2018. Developing higher-order thinking skill (HOTS) test instrument using Lombok local cultures as contexts for junior secondary school mathematics. Research and Evaluation in Education Journal

(http://journal.uny.ac.id/index.php /reid), diakses pada tanggal 13 Februari 2021.

Kemendikbud. 2017. Modul Penyusunan Soal Higher Order Thinking Skill
(HOTS). Dirjen Pendidikan Dasar dan Menengah.

Kusuma; Rosidin; Abdurrahman and Suyatna. $2017 . \quad$ The Development of Higher Order Thinking Skill (Hots) Instrument Assessment In Physics Study. IOSR Journal of Research \& Method in Education. (www.iosrjournals.org), diakses pada tanggal 13 Februari 2021.

Mardapi, Djemari. 2008. Pengukuran, Penilaian dan Evaluasi Pendidikan. Yogyakarta: Nuha Medika

Retnawati, Heri. 2016. Validitas, Reliabilitas, dan Karakteristik Butir. Yogyakarta: Parama Publishing

Rotherham, A. J., \& Willingham, D. 2009. 21st century. Educational leadership, 67(1), 16-21.

Saputra, Hatta. 2016. Pengembangan Mutu Pendidikan Menuju Era Global: Penguatan Mutu Pembelajaran dengan Penerapan HOTS (High Order Thinking Skills). Bandung: SMILE's Publishing.

Soeharto \& Rosmaiyadi. (2018). The Analysis of students' higher order thinking skills (HOTS) in Wave and Optics Using IRT with winstep Software. Journal of Educational Science and Technology. (http://dx.doi.org/10.26858/est.v1 i1.7001), diakses pada tanggal 13 Februari 2021.

Suherman, Erman. 2013. EvaluasiPembelajaran Matematika. Bandung: JICA UPI

Trilling, Bernie and Hood, Paul. 1999. Learsning, Technology, and Education Reform In The Knowledge Age. (Online), (https://www.wested.org/online_p ubs/learning_technology.pdf.), diakses tanggal 5 Maret 2020 
Widana, I Wayan. 2017. Modul Penyusunan Soal High Order

Thinking Skill (HOTS). Jakarta:

Direktorat Pembinaan Sma

Direktorat Jenderal Pendidikan

Dasar Dan Menengah

Departemen Pendidikan Dan Kebudayaan.
Yong, H. T., \& Sam, L. C. 2008. Implementing school-based assessment: The mathematical thinking assessment (MATA) framework. In Innovation and Pedagogy Seminar, Institute of Teacher Education, Sarawak. 